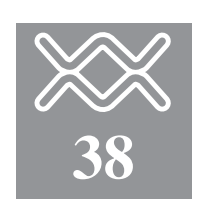

\title{
Infezione da HCV e trapianto di rene: esperienza del Centro di Bergamo
}

\author{
E. Gotti \\ Unità di Nefrologia e Dialisi \\ Dipartimento di Medicina Specialistica e dei Trapianti, \\ Ospedali Riuniti di Bergamo, Bergamo
}

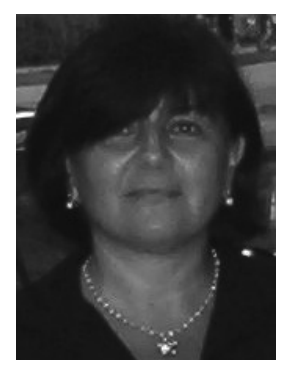

I

infezione da virus dell'epatite C $(\mathrm{HCV})$ è sicuramente la principale causa di epatopatia cronica nei pazienti sottoposti a trapianto renale. L'analisi dei dati fino a ora pubblicati sulla storia naturale dell'epatite $\mathrm{C}$ nei pazienti sottoposti a trapianto renale non permette di giungere a conclusioni certe, molte osservazioni si basano infatti su follow-up brevi o su dati retrospettivi in assenza di correlazioni clinico-istologiche. Va però sottolineato che $\mathrm{i}$ dati disponibili sembrano dimostrare che la positività per $\mathrm{HCV}$ si associ a una ridotta sopravvivenza sia del paziente che dell'organo trapiantato (1). Più controversa sembra invece essere la progressione del danno epatico nei pazienti portatori di epatite $\mathrm{C}$ cronica sottoposti a trapianto di rene. Le prime osservazioni sembravano suggerire una rapida perdita di funzione epatica successiva al trapianto (2). Tuttavia in questi studi la funzionalità epatica pre-trapianto non era stata valutata in modo approfondito, portando spesso a una sottostima della gravità del danno epatico al momento del trapianto. Valutazioni più recenti, eseguite mediante l'utilizzo della biopsia prima del trapianto, dimostrano che la maggior parte di pazienti con infezione da HCV e sottoposti a trapianto d'organo presenta un'evoluzione della malattia epatica relativamente lenta e asintomatica, in cui le alterazioni degli indici biochimici si evidenziano in meno del $50 \%$ dei pazienti trapiantati HCV positivi, per lo più caratterizzati da lieve o moderato incremento delle transaminasi $(2,3)$. Solo occasionalmente sono stati osservati nel trapianto renale casi di rapida evoluzione verso l'insufficienza epatica terminale.

\section{Gestione dell'infezione da $\mathrm{HCV}$ nel trapianto di rene}

Lo screening anti-HCV su potenziali donatori ha drasticamente ridotto il rischio di infezione post-trapianto. Per i candidati al trapianto, il rischio di essere anti HCV positivi, dipende principalmente dal numero di emotrasfusioni ricevute e dalla durata della dialisi. Osservazioni clinico-istologiche hanno evidenziato che il grado di severità istologica dell'epatite prima del trapianto costituisce un importante fattore prognostico nella successiva evoluzione clinica. Analogamente, anche la mortalità post-trapianto sembra essere significativamente correlata alla severità del quadro istologico pre-trapianto. Ciononostante, la condizione del paziente con infezione da $\mathrm{HCV}$ e trapianto d'organo potrebbe essere mi- gliorata ottimizzando la terapia antivirale e immunosoppressiva. Nel primo caso i dati non sono però incoraggianti. È stato infatti dimostrato che l'interferone alfa - il farmaco di riferimento per il trattamento dell'epatite $\mathrm{C}$ cronica - aumenta significativamente il rischio di rigetto nei pazienti sottoposti a trapianto d'organo (4), mentre non ci sono dati definitivi sul possibile rapporto rischio/beneficio di ribavirina e amantadina, due altri antivirali, in questi pazienti.

Anche la scelta della terapia immunosoppressiva potrebbe essere rilevante nella gestione del paziente trapiantato con infezione cronica da HCV. Alcuni studi sperimentali hanno dimostrato che la ciclosporina inibisce la replicazione del virus a livello intracellulare, un effetto che non è stato evidenziato con il tacrolimus, un altro inibitore della calcineurina (5). Osservazioni più recenti hanno portato a ipotizzare che anche il micofenolato mofetil potrebbe inibire la replicazione virale, mentre gli steroidi sembrano avere effetti opposti (6). Nel tentativo quindi di bloccare la replicazione del virus, cercando di fronteggiare l'eccesso di morbidità e mortalità nei pazienti con infezione da $\mathrm{HCV}$ già sottoposti a trapianto, vi è la tendenza, in molti Centri, a ridurre o sospendere la terapia steroidea e l'azatioprina, introducendo l'impiego di nuovi farmaci immuno- 


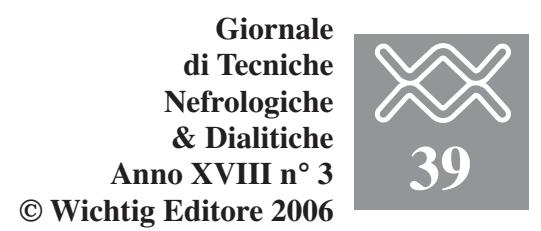

soppressori, come ad esempio il micofenolato mofetil. Il ruolo di tali strategie sull'evoluzione dell'epatopatia è comunque ancora controverso.

\section{Infezione da $\mathrm{HCV}$ e trapianto di rene: l'esperienza di Bergamo}

È nostra prassi non escludere a priori pazienti $\mathrm{HCV}$ positivi che intendano sottoporsi a trapianto di rene. Consigliamo la valutazione di HCV RNA quantitativo e qualitativo e dell'andamento delle transaminasi. Dopo aver eseguito tali valutazioni, si prospettano diversi scenari possibili:

1. Nel caso di positività di HCV RNA con normale andamento delle transaminasi e assenza, comunque, di epatopatia, consideriamo idoneo il paziente al trapianto. La funzione epatica e l'andamento della carica virale vengono strettamente monitorati dopo il trapianto.

2. Nel caso di positività di HCV RNA con movimento delle transaminasi e identificazione del genotipo, consigliamo l'esecuzione di biopsia epatica. Se si evidenzia un quadro di epatite cronica di grado moderato o severo, in accordo con gli epatologi, viene impostato il trattamento antivirale. Il paziente viene rivalutato per il trapianto solo dopo "guarigione" dell'epatopatia.

3. In casi estremi in cui la terapia sia stata inefficace, ci sia grave compromissione della funzione epatica, e il paziente sia giovane, viene considerata la possibilità di trapianto combinato fegato-rene.

Dal novembre 1989 al novembre 2005 sono stati effettuati presso il nostro Centro 558 trapianti di rene. La positività per il virus dell'epatite $\mathrm{C}$ si è osservata in 64 pazienti. Tutti erano positivi prima del trapianto. Seguendo il protocollo sopra descritto, i risultati sono stati i seguenti:

- In 2 pazienti trattati con Interferonalfa prima del trapianto, si è ottenuta la negativizzazione di HCV RNA e normalizzazione delle transaminasi. Dopo il trapianto, effettuato ormai in entrambi i casi, da diversi anni, la funzione epatica rimane nel range di normalità. Permane positività di HCV con HCV RNA negativo. - Tre pazienti sono stati sottoposti a trapianto combinato fegato-rene. In uno di questi si è avuta la recidiva di epatite HCV correlata e crioglobulinemia. Il paziente è stato trattato con PEG Interferon-alfa e ribavirina, con buona risposta virologica e umorale. Dei restanti 59 pazienti HCV positivi, solo 5 hanno presentato, durante il periodo di osservazione, movimento delle transaminasi, incremento quantitativo di HCV RNA senza però necessità di procedere alla biopsia epatica e/o trattamento antivirale. L'atteggiamento terapeutico in questi pazienti è stato quello di evitare l'impiego di azatioprina e utilizzare protocolli terapeutici che prevedessero dosi ridotte di steroidi e ciclosporina. È importante sottolineare che nessuno ha presentato evoluzione cirrogena.

\section{CONCLUSIONI}

Dalla letteratura emerge che l'infezione da HCV di per sé non costituisce una controindicazione assoluta al trapianto di rene. I pazienti HCV positivi vanno attentamente studiati e monitorati nella fase pre-trapianto, al fine di definire in modo preciso e dettagliato lo stato della funzione del fegato. Da questo punto di vista, la biopsia epatica pre-trapianto trova sicuramente indicazioni; per i pazienti con quadro istologico di epatite cronica è auspicabile l'applicazione di protocolli terapeutici in grado di eradicare l'infezione prima del trapianto. Sono invece necessari ulteriori strumenti terapeutici per il trattamento del paziente con epatite $\mathrm{C}$ cronica nella fase post-trapianto, considerato che i farmaci oggi a disposizione hanno un'efficacia limitata in questi pazienti, associandosi inoltre spesso a un profilo di tossicità inaccettabile. Attualmente c'è un generale accordo circa la controindicazione al solo trapianto di rene nei pazienti con cirrosi, per i quali, in casi selezionati, può invece essere considerato il trapianto combinato fegato-rene.

\section{BIBLIOGRAFIA}

1. Batty DS Jr, Swanson SJ, Kirk AD, Ko CW, Agodoa LY, Abbott KC. Hepatitis $C$ virus seropositivity at the time of renal transplantation in the United States: associated factors and patient survival. Am J Transplant 2001; 1: 179-84.

2. Bloom RD, Lake JR. Emerging issues in hepatitis $\mathrm{C}$ virus-positive liver and kidney transplant recipients. Am J Transplant 2006; 6: 2232-7.

3. Kamar N, Rostaing L, Selves J, et al. Natural history of hepatitis $\mathrm{C}$ virus-related liver fibrosis after renal transplantation. Am J Transplant 2005; 5: 1704-12.

4. Baid S, Tolkoff-Rubin N, Saidman S, et al. Acute humoral rejection in hepatitis C-infected renal transplant recipients receiving antiviral therapy. Am J Transplant 2003; 3: 74-8.

5. Abbott KC, Bucci JR, Matsumoto CS, et al. Hepatitis $\mathrm{C}$ and renal transplantation in the era of modern immunosuppression. J Am Soc Nephrol 2003; 14: 2908-18.

6. Lake JR. The role of immunosuppression in recurrence of hepatitis C. Liver Transpl 2003; 9 (Suppl): S63-6. 